\title{
Karakteristik Kulit Kokon Segar Ulat Sutera Liar (Attacus atlas) dari Perkebunan Teh di Daerah Purwakarta
}

\section{The Characteristics of Fresh Skin Cocoon of Attacus atlas from Tea Plantation in Purwakarta}

\author{
A. Baskoro ${ }^{1}$, A.M. Fuah $^{1}$ dan D.R. Ekastuti ${ }^{2}$ \\ ${ }^{1}$ Departemen Ilmu produksi dan Teknologi Peternakan, Fakultas Peternakan IPB \\ ${ }^{2}$ Fakultas Kedokteran Hewan Institut Pertanian Bogor \\ Jl. Agatis Kampus IPB Darmaga Bogor, 16680 \\ e-mail: asnath_95@yahoo.com
}

(Diterima: 13 April 2011; Disetujui: 10 Agustus 2011)

\begin{abstract}
Attacus atlas is known as wild silk moth that produce cocoon, the cocoon produce silk and have a great economics potential. This research was aimed to collect data and information about the cocoon that taken from the tea garden, Purwakarta. Variables measured in this study were cocoon characteristics and morfometrics such as cocoon weight (whole cocoon husk, cocoon husk without floss and floss weight), percentage of cocoon husk without floss weight from whole cocoon husk, percentage of floss weight from whole cocoon husk, cocoon lenght, circumference of cocoon, diameter of cocoon and the cocoon colour. Cocoon wight and the cocoon morfometrics were variable, indicated by the results obtained, such as whole cocoon husk (0.2-1.86 g), cocoon husk without floss $(0.14-1.65 \mathrm{~g})$, percentage of cocoon husk without floss weight from whole cocoon husk (42.59-91.09\%), floss weight $(0.04-0.38 \mathrm{~g})$, percentage of floss weight from whole cocoon husk $(8.91-57.41 \%)$, cocoon length $(3.37-6.81 \mathrm{~cm})$, diameter (anterior, medial and posterior) of cocoon $(1.6-2.98 \mathrm{~cm} ; 1.94-3.4 \mathrm{~cm} ; 1.5-2.91 \mathrm{~cm})$, circumference (anterior, medial, and posterior) of cocoon $(2.94-8.82 \mathrm{~cm} ; 4.91-10.02 \mathrm{~cm} ; 4.92-$ $8.33 \mathrm{~cm}$ ) and cocoon colour was classed into three class; light (32 cocoon or 12.8\%); medium (170 cocoon or 68\%); and dark (48 cocoon or 19.2\%). The values of morfometrics of cocoon varies because the observed cocoon is not clearly known whether it is male or female moth.
\end{abstract}

Keywords: Attacus atlas, cocoon morfometric, cocoon characteristic

\section{PENDAHULUAN}

Attacus atlas merupakan salah satu ulat sutera liar yang menghasilkan benang sutera dengan ciri khas yang berbeda dengan ulat sutera murbei (Bombyx mori). Kokon ulat sutera Attacus atlas memiliki nilai ekonomis yang tinggi dibandingkan dengan kokon sutera murbei. Kokon ulat sutera liar Attacus atlas dapat dijadikan berbagai macam produk seperti barang kerajinan tangan, pakaian jadi dan lain-lain .

Klasifikasi ulat sutera liar (Attacus atlas) menurut Peigler (1989), yaitu sebagai berikut, filum arthropoda, kelas insecta, ordo lepidoptera, super famili bombycoidea, famili saturniidae, sub famili saturniinae, genus attacus, spesies attacus atlas.

Ulat sutera liar (Attacus atlas) ini merupakan plasma nutfah yang banyak terdapat di Indonesia, sehingga pelestariannya sangat diperlukan. Penelitian tentang budidaya ulat sutera liar (Attacus atlas) masih dilakukan di alam bebas dengan tingkat keberhasilan hanya $10 \%$. Ulat sutera liar (Attacus atlas) mengalami metamorphosis sempurna, yaitu siklus hidupnya dimulai dari telur - larva - pupa imago (Awan, 2007). Benang sutera yang dihasilkan oleh ulat sutera liar (Attacus atlas) memiliki keunikan, yaitu memiliki warna tanpa harus melalui proses 
pencelupan. Kokon ulat sutera liar (Attacus atlas) menghasilkan benang beraneka warna cokelat dari yang terang sampai yang gelap.

Tujuan dari penelitian ini adalah untuk mengetahui karakteristik kokon dari ulat sutera liar (Attacus atlas) yang berasal dari perkebunan teh yang ada di daerah Purwakarta. Hasil yang diperoleh dapat digunakan sebagai informasi yang berguna bagi penelitian selanjutnya dan upaya-upaya untuk meningkatkan produktivitas ulat sutera liar (Attacus atlas) di Indonesia.

\section{METODE}

\section{Lokasi dan Waktu}

Penelitian ini dilaksanakan dari bulan September - November 2007. Penelitian dilakukan di Laboratorium Non-Ruminansia dan Satwa Harapan (NRSH) Fakultas Peternakan Institut Pertanian Bogor, Bogor.

\section{Materi}

Materi yang digunakan dalam penelitian ini adalah kokon ulat sutera liar (Attacus atlas) yang diambil dari perkebunan teh di daerah Purwakarta sebanyak 250 kokon. Kokon yang akan digunakan dalam penelitian ini adalah kokon yang di dalamnya sudah tidak ada pupanya atau ngengat sudah keluar dari kokonnya.

Alat-alat yang digunakan adalah timbangan digital merk "ADAM" dengan ketelitian 0,01 gram, kamera digital, benang untuk mengukur lingkar kokon, serta jangka sorong merk "TRICLE BRAND" untuk mengukur panjang dan diameter kokon.

\section{Prosedur Penelitian}

Kokon ulat sutera liar (Attacus atlas) didapat dari perkebunan teh yang berada di daerah Purwakarta dengan cara mengambil secara langsung kokon yang sudah kosong (tidak ada pupa) dari pohon teh.

Kokon yang didapat dibawa ke laboratorium untuk kemudian diukur sesuai dengan peubah yang diamati. Kokon ditimbang dengan menggunakan timbangan digital merk " $A D A M$ " dengan ketelitian sampai 0,01 gram.
Bobot kulit kokon dikelaskan menjadi sembilan kelas menurut Walpole (1992), yaitu:

Kelas = 1+3,33 Log n...(n=jumlah sample)

Pengukuran panjang, diameter dan lingkar kokon dilakukan setelah kokon dipisahkan dengan flossnya.

Warna kokon dikelompokkan berdasarkan standar warna yang sudah dibuat yaitu light, medium dan dark. Penelitian ini dilakukan dengan cara mengambil kokon secara purposive yakni kokon dari ulat sutera liar (Attacus atlas) yang berasal dari perkebunan teh di daerah Purwakarta sebanyak 250 kokon.

\section{Peubah yang diamati:}

1. Bobot Kulit Kokon Utuh (BKKU) (g)

Bobot kokon ditimbang setelah kulit kokon utuh dibersihkan dari kotoran dan kulit pupanya.

2. Bobot Kulit Kokon Tanpa Floss (BKKTF) (g)

Bobot kokon dapat diketahui setelah kokon utuh yang sudah dibuang flossnya ditimbang.

3. Persentase Bobot Kulit Kokon tanpa Floss terhadap Kulit kokon Utuh (PBKKTF) (\%)

Persentase kulit kokon tanpa floss terhadap kulit kokon utuh dihitung dengan cara membagi bobot kulit kokon tanpa floss dengan bobot kokon utuh dan dikalikan dengan $100 \%$.

4. Bobot Floss (BF) (g)

Floss dipisahkan dengan kokon atau dikupas kemudian ditimbang.

5. Persentase Bobot Floss terhadap Kulit Kokon Utuh (PBF) (\%)

Persentase floss terhadap kulit kokon utuh dihitung dengan cara membagi bobot floss dengan bobot kokon utuh dan dikalikan dengan $100 \%$.

6. Panjang Kokon (PK) (cm)

Panjang kokon diukur dengan menggunakan jangka sorong.

7. Diameter Kokon (cm)

Diameter diamati pada:

- $1 / 4$ bagian atas (D1)

- bagian tengah (D2) 
- 1/4 bagian dari bawah kokon (D3)

Diameter kokon diukur dengan menggunakan jangka sorong.

8. Lingkar Kokon (cm)

Lingkar kokon diamati pada:

- 1/4 bagian dari atas (L1)

- bagian tengah (L2)

- 1/4 bagian dari bawah kokon (L3).

Lingkar kokon diukur dengan menggunakan benang jahit dan jangka sorong.

\section{Warna}

Standar warna yang dibuat adalah light, medium dan dark. Pengkelasan warna dilakukan berdasarkan uji preferensi warna.

\section{Analisis Data}

Analisis data dilakukan terhadap karakteristik fisik kokon meliputi bobot kokon utuh, bobot floss, bobot kokon tanpa floss, panjang dan diameter kokon, lingkar kokon dan warna kokon . Data yang didapat ditabulasi kemudian dianalisis rataan dan keragaman secara deskriptif.

\section{HASIL DAN PEMBAHASAN}

Karakteristik dari kokon yang diambil dari perkebunan teh di daerah Purwakarta dapat dilihat pada Tabel 1. Bobot kulit kokon utuh memiliki ukuran berkisar antara 0,2-1,86 g dengan rataan sebesar 0,68 \pm 0.24 g. Bobot kulit kokon segar rata-rata ulat sutera liar (Attacus atlas) adalah 1,29 g (Awan, 2007), ini berarti ulat sutera liar memiliki keunggulan dibandingkan dengan kokon ulat sutera murbei (Bombyx mori). Bobot kulit kokon segar ulat sutera murbei (Bombyx mori) varietas murni berkisar antara 0,30-0,40 g, sedangkan untuk varietas hibrida berkisar antara 0,35-0,40 g (Atmosudarjo et al., 2000).

Bobot kulit kokon utuh segar ulat sutera liar (Attacus atlas) yang didapat dari perkebunan teh di daerah Purwakarta lebih besar daripada kulit kokon segar ulat sutera murbei (Bombyx mori) ini dikarenakan bobot larva dan konsumsi pakan ulat sutera liar (Attacus atlas) lebih banyak dan lebih besar dibandingkan dengan ulat sutera murbei (Bombyx mori).

Selang atau jarak antara nilai minimum dan maksimum bobot kulit kokon utuh (BKKU) cukup besar $(1,66 \mathrm{~g})$. Perbedaan nilai minimum dan maksimum kulit kokon utuh mungkin disebabkan karena tidak diketahui dengan jelas apakah kulit kokon yang diambil adalah berasal dari jantan atau betina karena kulit kokon yang diambil dan dijadikan sebagai materi penelitian adalah kokon yang sudah kosong atau sudah tidak ada pupanya. Pada umumnya ukuran kulit kokon ngengat betina lebih besar dibandingkan dengan ngengat jantan, tetapi tidak selalu kokon yang lebih kecil adalah kokon ngengat jantan. Terkadang kokon dari ngengat betina yang kecil sama dengan kokon dari ngengat jantan yang besar.

Faktor lain yang menyebabkan selang atau jarak antara nilai minimum dan maksimum (BKKU) cukup besar adalah tidak diketahui dengan jelas apakah kokon yang didapat adalah berasal dari varietas yang sama, karena Genus Attacus atau ngengat atlas menurut Peigler (1989) ada 50 jenis namun yang telah diproduksi hanya ada 14 jenis yaitu Attacus atlas Linnaeus, Attacus auranticus Rothschild, Attacus caesar Maassen, Attacus crameri Felder, Attacus dohertyi Rothschild, Attacus erebus Fruhstor, Attacus inopinatus Jurriaanse, Attacus intermedius Jurriaanse, Attacus lemairei Peigler, Attacus lorquinii, Attacus mcmulleni Watson, Attacus paraliae Peigler, Attacus taprobanis Moore, Attacus wardi Rotschild. Spesies Attacus yang banyak tersebar di wilayah Indonesia ada delapan, yaitu Attacus auranticus, Attacus dohertyi, Attacus intermedius, Attacus inopinatus, Attacus crameri, Attacus paraliae, Attacus erebus, Attacus atlas. Masing-masing spesies ini memiliki ciri dan ukuran kokon yang berbeda (Peigler, 1989).

Bobot kulit kokon utuh (BKKU) dikelaskan menjadi sembilan kelas menurut Wallpole (1992). Pengkelasan bobot kulit kokon utuh dilakukan untuk mengetahui pola persebaran dari bobot kulit kokon utuh 
ulat sutera liar (Attacus atlas) yang diambil dari perkebunan teh di daerah Purwakarta. Tabel 2 menunjukkan bahwa BKKU paling banyak berada pada kisaran antara 0,57-0,75 g $(31,6 \%)$. Bobot kulit kokon utuh yang lebih besar dari 1,13 hanya ada sedikit atau sebagian kecil saja 3,2\%.

Gambar 1 (grafik sebaran normal) menunjukkan bahwa bobot kulit kokon utuh (BKKU) menjulur ke kiri, ini berarti bahwa bobot kulit kokon utuh (BKKU) yang didapat dari perkebunan teh di daerah Purwakarta lebih banyak pada kisaran kurang dari $1 \mathrm{~g}$. terdapat pencilan, yaitu bobot kulit kokon utuh yang lebih besar dari $1,35 \mathrm{~g}$.

Dari pengkelasan BKKU ulat sutera liar (Attacus atlas) yang berasal dari perkebunan teh di daerah Purwakarta dapat dilakukan Grading atau pengklasifikasian mutu terhadap karakteristik kulit kokon (Tabel 3). Untuk menentukan kelas kokon digunakan langkah-langkah sebagai berikut, bobot kulit kokon utuh yang berasal dari perkebunan teh di daerah Purwakarta rata rata setelah dihitung adalah $0,68 \mathrm{~g}$, berarti masuk dalam kategori kelas C. Kelas mutu kulit kokon yang didapat dari perkebunan teh dari daerah Purwakarta jika dibandingkan dengan data Laboratorium (Tabel 4) maka kelas mutu kulit kokon yang didapat dari perkebunan teh di daerah Purwakarta adalah sangat jauh di bawah data Laboratorium (1,29 g) (Awan, 2007).

Tabel 1. Karakteristik kulit kokon yang berasal dari perkebunan teh di daerah Purwakarta

\begin{tabular}{|c|c|c|c|}
\hline No & Parameter & Nilai & \\
\hline & & $\begin{array}{l} \pm \text { Simpangan } \\
\text { Baku }\end{array}$ & $\begin{array}{l}\text { Minimum - } \\
\text { maksimum }\end{array}$ \\
\hline 1. & Bobot Kulit Kokon Utuh (BKKU) (g) & $0,68 \pm 0,24$ & $0,2-1,86$ \\
\hline 2. & Bobot Floss (BF) (g) & $0,18 \pm 0,05$ & $0,04-0,38$ \\
\hline 3. & Persentase Bobot Floss (PBF) (\%) & $27,61 \pm 6,12$ & $8,91-57,41$ \\
\hline 4. & $\begin{array}{l}\text { Bobot Kulit Kokon Tanpa Floss } \\
\text { (BKKTF) }(\mathrm{g})\end{array}$ & $0,50 \pm 0,2$ & $0,14-1,65$ \\
\hline 5. & $\begin{array}{l}\text { Persentase Boot Kulit Kokon Tanpa Floss } \\
\text { (PBKTF) }(\%)\end{array}$ & $72,39 \pm 6,12$ & $8,91-57,41$ \\
\hline 6. & Panjang Kokon (PK) $(\mathrm{cm})$ & $5,33 \pm 0,52$ & $3,37-6,81$ \\
\hline & $\begin{array}{l}\text { Diameter: } \\
\text { - } 1 / 4 \text { bagian anterior }(\mathrm{D} 1)(\mathrm{cm})\end{array}$ & $2,30 \pm 0,25$ & $1,6-2,98$ \\
\hline 7. & - $\quad$ Medial (D2) (cm) & $2,61 \pm 0,23$ & $1,94-3,4$ \\
\hline & - $1 / 4$ bagian posterior $(\mathrm{D} 3)(\mathrm{cm})$ & $2,17 \pm 0,22$ & $1,5-2,91$ \\
\hline & $\begin{array}{l}\text { Lingkar: } \\
\qquad 1 / 4 \text { bagian anterior }(\mathrm{L} 1)(\mathrm{cm})\end{array}$ & $6,87 \pm 0,73$ & $2,94-8,82$ \\
\hline 8. & - Medial (L2 )(cm) & $8,18 \pm 0,71$ & $4,91-10,02$ \\
\hline & - $1 / 4$ bagian posterior $(\mathrm{L} 3)(\mathrm{cm})$ & $6,42 \pm 0,62$ & $4,92-8,33$ \\
\hline
\end{tabular}

Keterangan : Nilai dalam kolom adalah nilai rataan \pm simpangan baku dan nilai minimum-maksimum 
Tabel 2. Pengkelasan bobot kulit kokon utuh

\begin{tabular}{cccc}
\hline No & Selang Kelas & Frekuensi & Persentase $(\%)$ \\
\hline 1 & $0,2-0,38$ & 26 & 10,4 \\
2 & $0,39-0,56$ & 57 & 22,8 \\
3 & $0,57-0,75$ & 79 & 31,6 \\
4 & $0,76-0,94$ & 52 & 20,8 \\
5 & $0,95-1,13$ & 28 & 11,2 \\
6 & $1,14-1,32$ & 6 & 2,4 \\
7 & $1,33-1,51$ & 1 & 0,4 \\
8 & $1,52-1,70$ & 0 & 0 \\
9 & $1,71-1,89$ & 1 & 0,4 \\
\hline
\end{tabular}

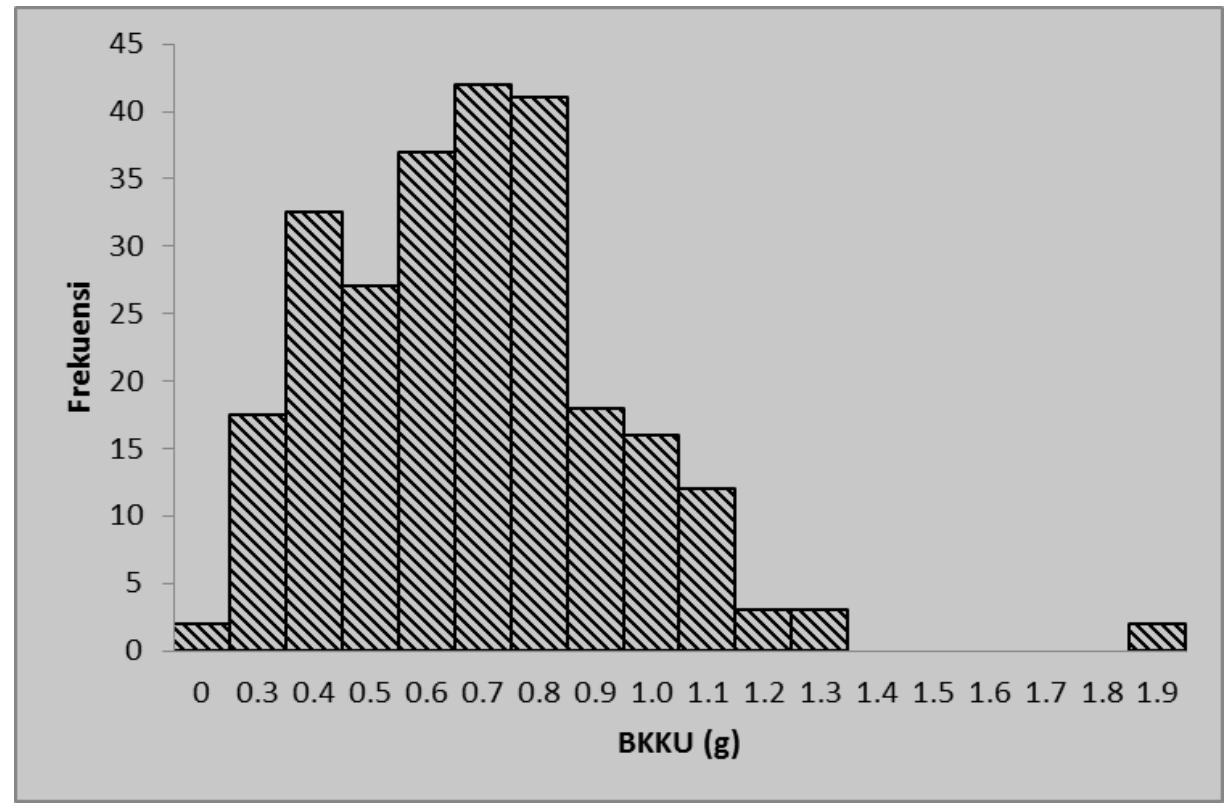

Gambar 1. Grafik sebaran normal bobot kulit kokon utuh (bkku)

Tabel 3. Klasifikasi bobot kulit kokon utuh (bkku) yang berasal dari perkebunan teh di daerah Purwakarta

\begin{tabular}{cccc}
\hline No & Bobot Kulit Kokon & Kelas Mutu (Grade) & Persentase dari Populasi (\%) \\
\hline 1 & $>0,88$ & A & 18,4 \\
2 & $0,74-0,88$ & B & 20,8 \\
3 & $0,62-0,73$ & C & 20,4 \\
4 & $0,45-0,61$ & D & 20,4 \\
5 & $<0,44$ & E & 20 \\
\hline
\end{tabular}

Tabel 4. Klasifikasi kulit kokon

\begin{tabular}{ccc}
\hline No & Bobot Kulit Kokon $(\mathrm{g})$ & Kelas Mutu (grade) \\
\hline 1 & $>2$ & $\mathrm{~A}$ \\
2 & $1,5-1,9$ & $\mathrm{~B}$ \\
3 & $1-1,4$ & $\mathrm{C}$ \\
4 & $<0,9$ & $\mathrm{D}$ \\
\hline
\end{tabular}

Sumber: Saleh, 2000; Moerdoko, 2002 dalam Awan, 2007 
Hal ini mungkin juga dapat disebabkan karena cekaman lingkungan yang didapat oleh ulat sutera liar (Attacus atlas) yang ada di alam liar lebih besar daripada ulat sutera liar (Attacus atlas) yang dipelihara di Laboratorium. Pengklasifikasian ini juga bertujuan agar dapat dikembangkan untuk menentukan harga jual dari kokon. Selain untuk membandingkan kualitas kokon yang didapat dari alam (liar) dengan data Laboratorium, dengan adanya standar mutu kokon para peternak dapat menentukan langkah-langkah budidaya yang sesuai agar menghasilkan kokon dengan kualitas yang baik.

\section{Bobot Floss}

Floss adalah bagian terluar dari kokon yang berfungsi sebagai kerangka awal dalam pembuatan kokon. Floss sebagai kerangka awal dalam pembuatan kokon dan sebagai pelindung yang terdapat pada bagian terluar dari kulit kokon dilekatkan pada daun atau ranting-ranting agar kokon tidak jatuh jika tertiup angin (Gambar 2). Bobot floss berkaitan dengan energi ekstra yang dihasilkan ulat sutera liar (Attacus atlas) selain untuk memproduksi kulit kokon yang dapat dipintal menjadi benang. Pakan pada umumnya digunakan oleh setiap makhluk hidup untuk pemeliharaan sel tubuh, perkembangan dan pertumbuhan serta untuk proses produksi. Proses produksi dalam hal ini adalah pakan digunakan untuk menghasilkan benang sutera. bobot floss ini akan semakin besar jika tempat pengokonan juga besar, hal ini menyebabkan ulat harus mengeluarkan energi yang besar untuk membuat kerangka (floss).

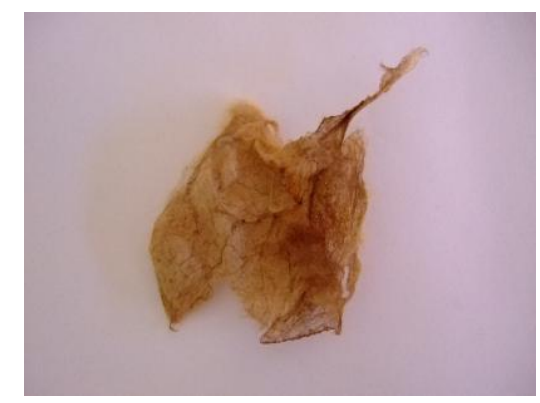

(1)
Bobot floss dikelaskan menjadi sembilan kelas seperti bobot kulit kokon utuh menurut Wallpole (1992). Pengkelasan bobot floss dilakukan untuk mengetahui pola persebaran dari bobot floss (BF) ulat sutera liar (Attacus atlas) yang diambil dari perkebunan teh di daerah Purwakarta. Bobot floss (BF) ulat sutera liar yang berasal dari perkebunan teh di daerah Purwakarta memiliki rataan bobot $0,18 \pm 0,02 \mathrm{~g}$. Bobot floss banyak yang terdapat pada kisaran 0,17-0,20 g (30\%), sedangkan bobot floss yang lebih besar dari $0,32 \mathrm{~g}$ hanya sekitar $1,2 \%$ saja dari populasi (Tabel 5). Grafík sebaran normal menunjukkan bahwa bobot floss (BF) menyebar normal (Gambar 3).

Klasifikasi mutu kokon dipengaruhi oleh bobot floss, semakin besar bobot floss, maka kualitas kulit kokon akan semakin jelek dan sebaliknya. Tabel 6 adalah peng klasifikasian bobot floss kokon ulat sutera liar Attacus atlas dari Purwakarta.

\section{Presentase Bobot Floss}

Persentase Bobot Floss (PBF) terhadap bobot kulit kokon utuh dihitung karena kualitas atau nilai mutu kokon akan semakin baik jika persentase bobot floss terhadap bobot kulit kokon utuh semakin kecil (Atmosoedarjo et al., 2000). Benang sutera dihasilkan dari kulit kokon tanpa floss, pada umumnya floss tidak dipintal untuk dijadikan benang. Semakin kecil persentase bobot floss terhadap kulit kokon utuh maka energi yang terbuang untuk membentuk floss akan dipakai untuk membentuk kulit kokon yang dapat dipintal menjadi benang, kualitas kokon akan semakin baik karena benang yang dihasilkan akan semakin banyak (Tabel 7 dan Tabel 8).

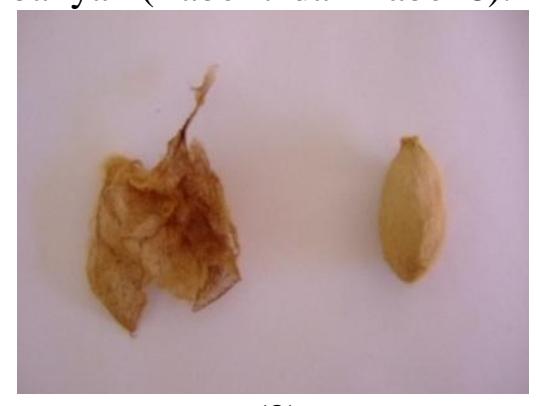

(2)

Gambar 2. (1) Floss; (2) Floss dan kulit kokon tanpa floss 
Tabel 5. Pengkelasan bobot floss

\begin{tabular}{cccc}
\hline No & Selang Kelas & Frekuensi & Persentase $(\%)$ \\
\hline 1 & $0,04-0,08$ & 9 & 3,6 \\
2 & $0,09-0,12$ & 31 & 12,4 \\
3 & $0,13-0,16$ & 58 & 23,2 \\
4 & $0,17-0,20$ & 75 & 30 \\
5 & $0,21-0,24$ & 43 & 17,2 \\
6 & $0,25-0,28$ & 19 & 7,6 \\
7 & $0,29-0,32$ & 12 & 4,8 \\
8 & $0,33-0,36$ & 2 & 0,8 \\
9 & $0,37-0,39$ & 1 & 0,4 \\
\hline
\end{tabular}

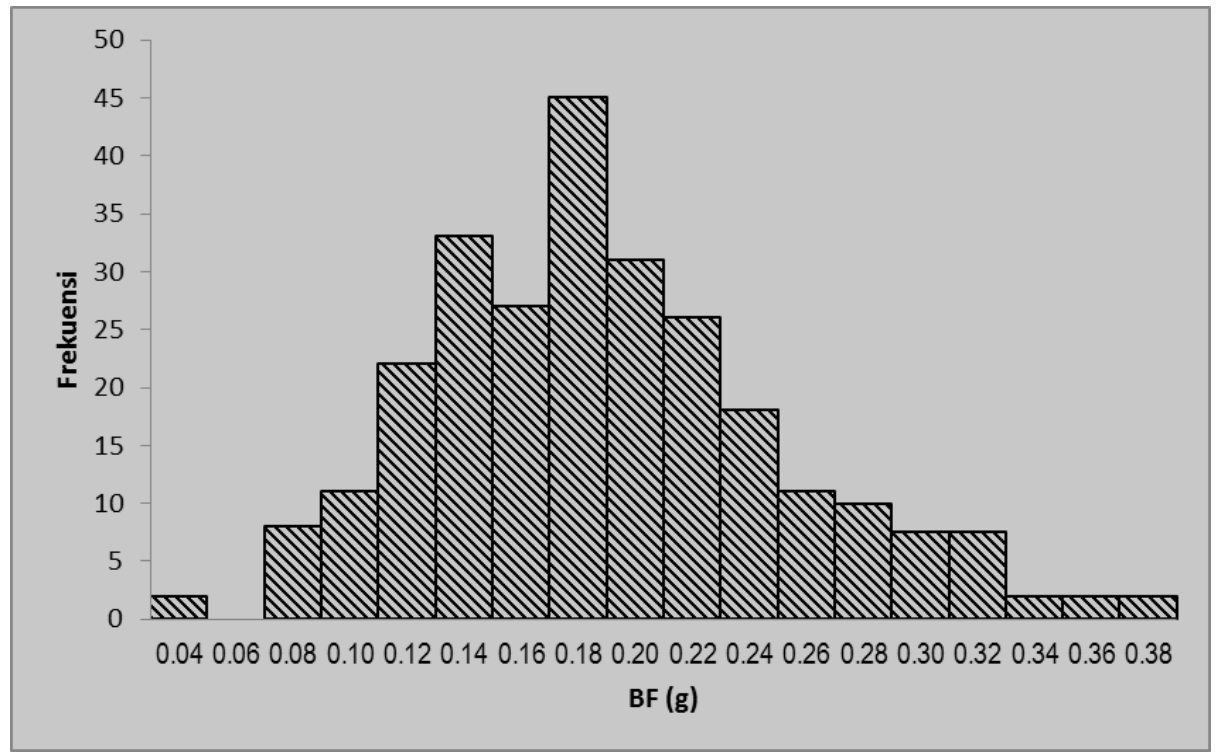

Gambar 3. Grafik sebaran normal bobot floss (BF)

Tabel 6. Klasifikasi bobot floss terhadap kulit kokon utuh (bf) yang berasal dari perkebunan teh di daerah Purwakarta

\begin{tabular}{cccc}
\hline No & Persentase Bobot Floss & Grade & Persentase dari Populasi (\%) \\
\hline 1 & $<0,14$ & A & 24,4 \\
2 & $0,14-0,16$ & B & 14,8 \\
3 & $0,17-0,19$ & C & 24,4 \\
4 & $0,2-0,23$ & D & 20,8 \\
5 & $>0,23$ & E & 15,6 \\
\hline
\end{tabular}

Tabel 7. Klasifikasi persentase bobot floss terhadap kulit kokon utuh (pbf) yang berasal dari perkebunan teh di daerah Purwakarta

\begin{tabular}{cccc}
\hline No & Persentase Bobot Floss & Grade & Persentase dari Populasi (\%) \\
\hline 1 & $<23,07$ & A & 19,2 \\
2 & $23,33-25,92$ & B & 20,8 \\
3 & $25,97-28,35$ & C & 25 \\
4 & $28,4-31,67$ & D & 20,4 \\
5 & $>31,67$ & E & 19,6 \\
\hline
\end{tabular}


Tabel 8. Klasifikasi kulit kokon

\begin{tabular}{ccc}
\hline No & Persentase Kulit Kokon $(\%)$ & Kelas Mutu (grade) \\
\hline 1 & $>25$ & $\mathrm{~A}$ \\
2 & $20-24,9$ & $\mathrm{~B}$ \\
3 & $15-19,9$ & $\mathrm{C}$ \\
4 & $<14,9$ & $\mathrm{D}$ \\
\hline
\end{tabular}

Sumber: Saleh, 2000; Moerdoko, 2002 dalam Awan, 2007

Tabel 9. Pengkelasan bobot kulit kokon tanpa floss

\begin{tabular}{cccc}
\hline No & Selang Kelas & Frekuensi & Persentase $(\%)$ \\
\hline 1 & $0,14-0,31$ & 53 & 21,2 \\
2 & $0,32-0,49$ & 77 & 30,8 \\
3 & $0,50-0,67$ & 74 & 29,6 \\
4 & $0,68-0,85$ & 38 & 15,2 \\
5 & $0,86-1,03$ & 6 & 2,4 \\
6 & $1,04-1,21$ & 1 & 0,4 \\
7 & $1,22-1,39$ & 0 & 0 \\
8 & $1,40-1,57$ & 0 & 0 \\
9 & $1,58-1,75$ & 1 & 0,4 \\
\hline
\end{tabular}

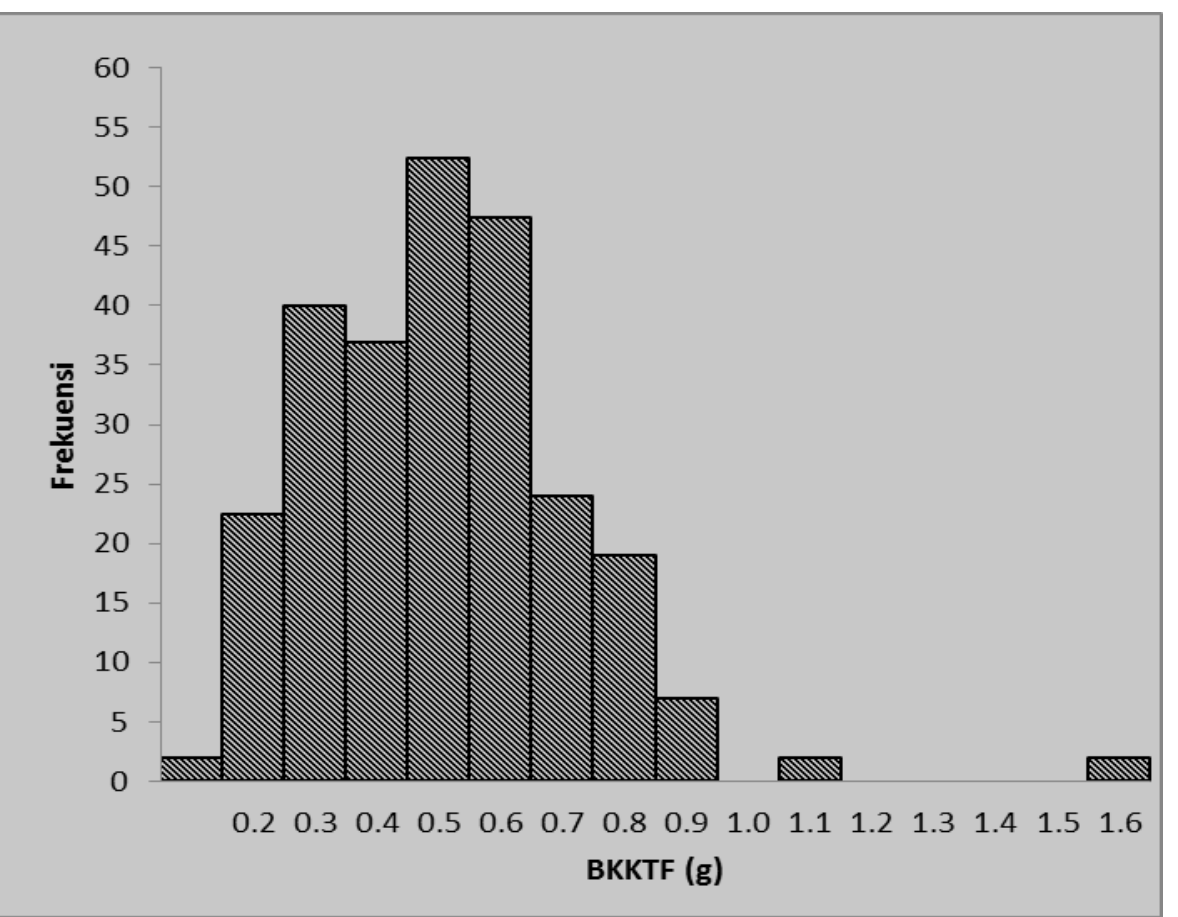

Gambar 4. Grafik sebaran normal bobot kulit kokon tanpa floss (bkktf)

\section{Bobot Kulit Kokon Tanpa Floss}

Bobot kulit kokon tanpa floss (BKKTF) adalah bobot kulit kokon utuh (BKKU) setelah dikurangi bobof floss (BF). Kulit kokon tanpa floss adalah bagian yang biasanya diseratkan menjadi benang dengan menggunakan mesin pintal. Benang yang sudah diseratkan dari kulit kokon tanpa floss dapat diolah menjadi berbagai macam produk seperti kain, pakaian jadi dan produk-produk kerajinan yang lain (Awan, 2007). Kulit kokon tanpa floss adalah bagian dalam setelah lapisan terluar (floss) pada saat memupa. Kulit kokon tanpa floss yang dihasilkan dari ulat sutera liar (Attacus atlas) yang berasal dari perkebunan daerah teh di 
daerah Purwakarta memiliki bobot rataan $0,50 \pm 0,01 \mathrm{~g}$.

Bobot kulit kokon tanpa floss (BKKTF) dikelaskan menjadi sembilan kelas seperti bobot kulit kokon utuh menurut Wallpole (1992). Pengkelasan bobot kulit kokon tanpa floss (BKKTF) dilakukan untuk mengetahui pola persebaran dari bobot kulit kokon tanpa floss (BKKTF) ulat sutera liar (Attacus atlas) yang diambil dari perkebunan teh di daerah Purwakarta (Tabel 9).

Grafík sebaran normal menunjukkan bahwa bobot kulit kokon tanpa floss (BKKTF) menyebar normal (Gambar 4). Gambar 4 menunjukkan bahwa terdapat pencilan, yaitu bobot kulit kokon tanpa floss (BKKTF) yang lebih besar dari 1,15 g.

Berdasarkan klasifikasi mutu BKKTF (Tabel 10) dapat diketahui bahwa kulit kokon tanpa floss ulat sutera liar (Attacus atlas) yang berasal dari perkebunan teh yang ada di daerah Purwakarta masuk dalam kriteria kelas $\mathrm{C}$, karena BKKTF rata-ratanya adalah $0,50 \pm 0,01 \mathrm{~g}$.

\section{Persentase Bobot Kulit Kokon Tanpa Floss (PBKTF) (\%)}

Persentase Bobot kokon tanpa floss (PBKTF) terhadap bobot kulit kokon utuh dihitung karena kualitas atau nilai mutu kokon akan semakin baik jika persentase bobot kulit kokon tanpa floss terhadap bobot kulit kokon utuh semakin besar (Atmosoedarjo et al., 2000). Benang sutera dihasilkan dari kulit kokon tanpa floss (BKKTF). Semakin besar persentase bobot kulit kokon tanpa floss (PBKTF) maka kualitas kokon akan semakin baik dan benang yang dihasilkan juga semakin banyak (Tabel 10).

\section{Analisis Korelasi dan Regresi}

Analisis korelasi adalah analisis untuk mengetahui hubungan antara dua peubah bebas. Hubungan ini bias berupa hubungan yang linier dan non-linier. Korelasi mengukur hubungan antar peubah, bukan mengkaji hubungan kausalitas (sebabakibat). Korelasi menggambarkan keeratan hubungan yang dimiliki oleh satu peubah dengan peubah yang lain. Nilai korelasi yang besar dapat digunakan sebagai acuan sehingga dapat memudahkan untuk menduga kualitas kulit kokon (seleksi) di lapang. Nilai korelasi berkisar dari -1 sampai $1(-1<\mathrm{r}<$ $+1)$. Nilai korelasi lebih dari nol $(\mathrm{r}>0)$ menandakan hubungan antara dua sifat tersebut adalah positif, artinya setiap kenaikan satu satuan sifat akan diikuti oleh sifat yang lain. Nilai korelasi kurang dari nol $(\mathrm{r}<0)$ menandakan hubungan antara dua sifat tersebut adalah negatif, artinya setiap kenaikan satu satuan sifat akan diikuti dengan penurunan sifat yang lain. Nilai korelasi yang semakin besar menandakan hubungan antara dua sifat tersebut sangat erat.

Nilai korelasi nol dapat berarti tidak terdapat hubungan (saling bebas) antara dua sifat yang diamati (tidak berkorelasi). Nilai korelasi nol tidak selalu berarti tidak berkorelasi, mungkin terdapat korelasi tetapi sangat kecil (mendekati nol).

Analisis regresi berguna untuk menelaah hubungan antara sepasang peubah atau lebih terutama untuk menelusuri pola hubungan yang modelnya belum diketahui dengan sempurna sehingga dalam penerapannya lebih bersifat eksploratif dan mengukur pada pendekatan empiris. Bobot kulit kokon ulat sutera liar (Attacus atlas) yang berasal dari perkebunan teh di daerah Purwakarta memiliki hubungan-hubungan korelasi dengan peubah-peubah yang lain. Hubungan antar peubah yang diamati dapat berupa hubungan yang positif ataupun negatif. Peubah yang diamati dalam penelitian ini dianalisis dengan menggunakan analisis regresi untuk menentukan model terbaik yang dapat digunakan untuk menjelaskan hubungan antar peubah-peubah yang diamati dalam penelitian ini. Dalam penelitian ini digunakan model regresi linier model ini dianggap lebih sederhana.

Nilai korelasi peubah-peubah yang diamati pada kulit kokon ulat sutera liar (Attacus atlas) yang berasal dari perkebunan teh di daerah di Purwakarta dapat dilihat pada Tabel 11. Bobot kulit kokon utuh 
(BKKU) memiliki nilai korelasi terhada lingkar tengah (medial) kokon lebih tinggi dibandingkan dengan diameter tengah (medial) kokon ataupun panjang kokon. Untuk menduga bobot kulit kokon utuh (BKKU) di lapangan lebih baik menggunakan pendekatan dengan lingkar. Dengan demikian peternak tidak memerlukan alat khusus untuk menduga bobot kulit kokon utuh (BKKU), peternak cukup membawa benang dan penggaris untuk mengukur lingkar kulit kokon.

\section{Morfometrik}

Morfometrik kulit kokon (Attacus atlas) bila dilihat dari panjang kokon $5,33 \pm 0,52 \mathrm{~cm}$, diameter $1 / 4$ bagian anterior $2,30 \pm 0,25 \mathrm{~cm}$, diameter medial 2,61 $\pm 0,232$ $\mathrm{cm}$, dan $1 / 4$ bagian posterior $17 \pm 0,22 \mathrm{~cm}$, serta lingkar kulit kokon 1/4 bagian anterior $6,87 \pm 0,73 \mathrm{~cm}$, medial $8,18 \pm 0,71 \mathrm{~cm}$ dan $1 / 4$ bagian posterior $6,42 \pm 0,62 \mathrm{~cm}$ menggambarkan bentuk kulit kokon yang normal dari ulat sutera liar (Attacus atlas) adalah

Tabel 10. Klasifikasi bobot kulit kokon tanpa floss terhadap kulit kokon utuh (bkktf) yang berasal dari perkebunan teh di daerah Purwakarta

\begin{tabular}{cccc}
\hline No & Bobot Kulit Kokon Tanpa Floss & Grade & $\begin{array}{c}\text { Persentase dari } \\
\text { Populasi (\%) }\end{array}$ \\
\hline 1 & $>0,66$ & A & 19,2 \\
2 & $0,55-0,66$ & B & 19,6 \\
3 & $0,45-0,54$ & C & 21,2 \\
4 & $0,31-0,44$ & D & 20 \\
5 & $<0,3$ & E & 20 \\
\hline
\end{tabular}

Tabel 11. Klasifikasi persentase bobot kulit kokon tanpa floss terhadap kulit kokon utuh (pbktf) yang berasal dari perkebunan teh di daerah Purwakarta

\begin{tabular}{cccc}
\hline No & Persentase Kulit Kokon Tanpa Floss & Grade & Persentase dari Populasi (\%) \\
\hline 1 & $>76,67$ & A & 19,2 \\
2 & $74,19-76,67$ & B & 20 \\
3 & $71,69-74,13$ & C & 20 \\
4 & $68,33-71,68$ & D & 20 \\
5 & $<68,33$ & E & 20,8 \\
\hline
\end{tabular}

Tabel 12. Korelasi peubah yang diamati terhadap kulit kokon segar ulat sutera liar (Attacus atlas) yang berasal dari perkebunan teh di daerah Purwakarta

\begin{tabular}{lccccc}
\hline & BKKU $(\mathrm{g})$ & BKKTF $(\mathrm{g})$ & BF $(\mathrm{g})$ & PBKTF $(\%)$ & PBF $(\%)$ \\
\hline BKKTF $(\mathrm{g})$ & 0,982 & & & & \\
BF $(\mathrm{g})$ & 0,777 & 0,646 & & & \\
PBKTF $(\%)$ & 0,428 & 0,570 & $-0,170$ & & \\
PBF $(\%)$ & $-0,428$ & $-0,570$ & 0,170 & $-1,000$ & \\
PK $(\mathrm{cm})$ & 0,578 & 0,548 & 0,224 & 0,224 & $-0,224$ \\
Diameter: & & & & & \\
- D1 $(\mathrm{cm})$ & 0,673 & 0,626 & 0,145 & 0,145 & $-0,145$ \\
- D2 $(\mathrm{cm})$ & 0,634 & 0,573 & 0,057 & 0,057 & $-0,057$ \\
- D3 $(\mathrm{cm})$ & 0,584 & 0,534 & 0,130 & 0,130 & $-0,130$ \\
Lingkar: & & & & & \\
- L1 $(\mathrm{cm})$ & 0,557 & 0,519 & 0,143 & 0,143 & $-0,143$ \\
- L2 $(\mathrm{cm})$ & 0,729 & 0,681 & 0,175 & 0,175 & $-0,175$ \\
- L3 $(\mathrm{cm})$ & 0,571 & 0,524 & 0,147 & 0,147 & $-0,147$ \\
\hline
\end{tabular}


elips dan bila kulit kokon segar ulat sutera liar (Attacus atlas) dibandingkan dengan kulit kokon ulat sutera murbei (Bombyx mori) maka kulit kokon ulat sutera liar (Attacus atlas) memiliki ukuran yang lebih besar (Gambar 5).

\section{Warna Kulit Kokon}

Warna kulit kokon ulat sutera liar Attacus atlas sangat bervariasi dari coklat muda hingga coklat tua. Warna alami benang yang eksotis dari kokon ulat sutera liar (Attacus atlas) merupakan salah satu ciri khas dan keunggulan, karena warna yang dihasilkan tanpa harus melalui proses pewarnaan atau pencelupan. Ciri khas inilah yang membut benang sutera dari kokon ulat sutera liar (Attacus atlas) sangat diminati dan memiliki harga jual yang tinggi (Kompas, 2004; Sriyono, 2003). Warna kulit kokon ulat sutera liar yang berasal dari perkebunan teh di daerah Purwakarta dikelompokkan menjadi tiga kelompok yaitu light, medium dan dark ( Dedy Duryadi et. al., 2010).
Bobot kulit kokon utuh (BKKU), bobot kulit kokon tanpa floss (BKKTF) dan bobot floss (BF) tidak dipengaruhi oleh warna. Hal ini dapat dilihat dari hasil analisis Korelasi Rank Spearman bahwa tidak terdapat bukti bahwa warna kokon mempengaruhi bobot kokon (nilai $\mathrm{P}=0,905622 ; \mathrm{P}>0,05$ ).

\section{Karakteristik Kulit Kokon}

Karakteristik kulit kokon segar ulat sutera liar (Attaus atlas) yang berasal dari perkebunan teh di daeerah Purakarta dapat memberikan informasi tentang Grading dan dapat digunakan sebagai pembanding dengan daerah-daerah lain yang ada di Indonesia. Data dari penelitian ini dapat digunakan sebagai data dasar untuk penelitian-penelitian lain dalam bidang produksi, genetika dan upaya peningkatan melalui budidaya yang tepat. Dengan demikian informasi ini juga dapat berguna dalam penetapam harga kulit kokon dan harga benang sutera (Attacus atlas).

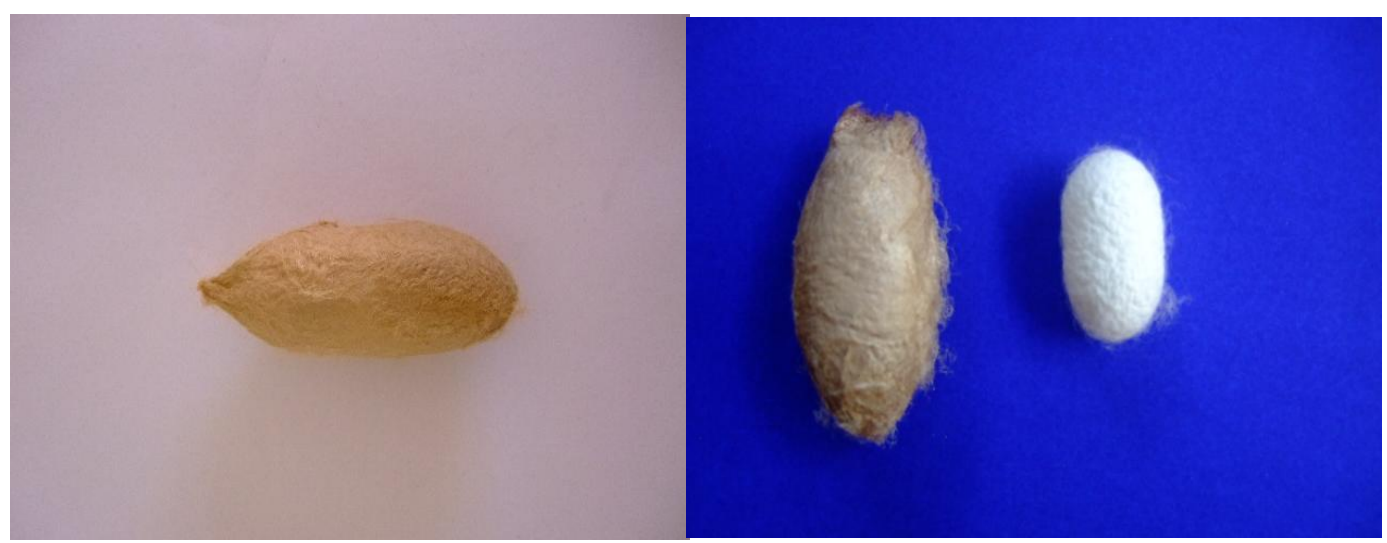

(1)

(2)

Gambar 5. (1) Bentuk kokon Attacus atlas; (2) Kokon Attacus atlas (kiri) dan kokon ulat sutera murbei (Bombyx mori)

Tabel 13. Pengkelasan warna kulit kokon yang berasal dari perkebunan teh di daerah Purwakarta

\begin{tabular}{ccc}
\hline Warna & Frekuensi & Persentase $(\%)$ \\
\hline Light & 48 & 19,2 \\
Medium & 170 & 68 \\
Dark & 32 & 12,8 \\
\hline
\end{tabular}




\section{KESIMPULAN DAN SARAN}

\section{Kesimpulan}

Dari berbagai peubah yang diamati dalam penelitian ini diketahui bahwa kulit kokon ulat sutera liar (Attacus atlas) yang diambil dari perkebunan teh di daerah Purwakarta sangat bervariasi dalam bobot kulit kokon. Keragaman ini disebabkan karena faktor lingkungan yang tidak dapat dikontrol. Bobot kulit kokon utuh (BKKU) $0,68 \pm 0,24 \mathrm{~g}$ dan bobot kulit kokon tanpa floss (BKKTF) 0,50 $\pm 0,2 \mathrm{~g}$, jika dibandingkan dengan kokon ulat sutera murbei (Bombyx mori) varietas hibrida $(0,35-0,55 \mathrm{~g})$ maka mutu kulit kokon ulat sutera liar (Attacus atlas) yang berasal dari perkebunan teh di daerah Purwakarta masih dibawah kokon ulat sutera murbei. Untuk menduga bobot kulit kokon tanpa floss (BKKTF) lebih baik menggunakan pendekatan pengukuran lingkar tengah kokon karena memiliki nilai korelasi yang besar $(0,681)$ dibandingkan dengan diameter tengah $(0,573)$ dan panjang kokon $(0,548)$. Bentuk dari kulit kokon dari ulat sutera liar (Attacus atlas) adalah elips. Warna kokon ulat sutera liar (Attacus atlas) dipengaruhi oleh genetik dan pakan.

\section{Saran \\ Masih diperlukan penelitian-} penelitian lebih lanjut dalam proses penyeratan, teknik penyeratan, kualitas benang, panjang benang dan penelitianpenelitian dalam bidang budidaya, genetika sebagai data dasar dalam upaya meningkatkan kualitas kulit kokon ulat sutera liar (Attacus atlas).

\section{DAFTAR PUSTAKA}

Atmosudarjo, H., J. Kartasubrata, M. Kaomini, W. Saleh, W. Moerdoko. 2000. Sutera Alam Indonesia. Yayasan Sarana Wana Jaya, Jakarta.

Awan, A. 2007. Aspek biologi ulat sutera liar Attacus atlas (Lepidoptera :
Saturniidae) pada tanaman sirsak (Annona muricata L.). Proceeding Kongres dan Seminar Nasional Entomologi VII, Bali.

Dingle, J.G., E. Hassan, M. Gupta, D. George, L. Anota, and H. Begum, 2005. Silk Production in Australia. RIRDC Publication No 05/145

Kompas. 2004. Permintaan Sutra Liar Tak Terbatas. http://kompas.com/kompascetak/0411/04/Jabar/1366508.htm. [2 Agustus 2007]

Megawati. 2005. Kualitas koon ulat sutera (Bombyx mori L.) berdasarkan perbedaan saat masuk ke pengokonan. Skripsi. Program Studi Teknologi Produksi Ternak. Fakultas Peternakan, Institut Pertanian Bogor, Bogor.

Nazar, A., 1990. Beberapa aspek biologi ulat perusak daun (Attacus atlasLinn) pada tanaman cengkeh. J. Penel. Tan. Ind. XVI (I). Pusat Penelitian dan Pengembangan Tanaman Industri, Bogor.

Peigler, R. S. 1989. A Revision of Indo Australian Genus Attacus. The Lepidoptera Research Foundation, Inc. Beverly Hills, California.

Peigler, R. S., 1989. A Revision of Indo Australian Genus Attacus. The Lepidoptera Research Foundation Inc., Beverly Hills, California.

Situmorang, J., 1996. An Attemp to Produce Attacus atlas L. Using Baringtonia Leaves as Plant Fooder. Int. J. Of Wild Silkmoth and Silk 1: 25-29.

Solihin, D.D., A. M. Fuah, S. S. Mansjoer, K. G. Wiryawan, D. R. Ekastuti, H. C. H. Siregar, D. J. Setyono, B. N. Polii, 2010. Budidaya Ulat Sutera Alam Attacus atlas. Penebar Swadaya, Jakarta

Walpole, R. E. 1992. Pengantar Statistika. 3 rd Edition. P.T. Gramedia Pustaka Utama, Jakarta. 